\title{
Synthesis, Spectroscopic, and Magnetic Studies of Mono- and Polynuclear Schiff Base Metal Complexes Containing Salicylidene-Cefotaxime Ligand
}

\author{
J. R. Anacona, ${ }^{1}$ Johan Calvo, ${ }^{1}$ and Ovidio A. Almanza ${ }^{2}$ \\ ${ }^{1}$ Departamento de Quimica, Universidad de Oriente, Cumana, Venezuela \\ ${ }^{2}$ Departamento de Física, Universidad Nacional de Colombia, Bogotá, Colombia \\ Correspondence should be addressed to J. R. Anacona; juananacona@hotmail.com
}

Received 11 February 2013; Revised 9 April 2013; Accepted 9 April 2013

Academic Editor: Wolfgang Linert

Copyright (c) 2013 J. R. Anacona et al. This is an open access article distributed under the Creative Commons Attribution License, which permits unrestricted use, distribution, and reproduction in any medium, provided the original work is properly cited.

\begin{abstract}
Metal complexes of a Schiff base ligand derived from cefotaxime and salicylaldehyde were prepared. The salicilydene-cefotaxime ligand $\left(\mathrm{H}_{2} \mathrm{~L}\right)$ and mononuclear $[\mathrm{M}(\mathrm{L})](\mathrm{M}(\mathrm{II})=\mathrm{Co}, \mathrm{Ni}$ and $\mathrm{Cu})$, dinuclear $\left[\mathrm{Ag}_{2}(\mathrm{~L})(\mathrm{OAc})_{2}\right]$, and tetranuclear metal complexes $\left[\mathrm{M}_{4}(\mathrm{~L})(\mathrm{OH})_{6}\right](\mathrm{M}(\mathrm{II})=\mathrm{Ni}, \mathrm{Cu})$ were characterized on the basis of analytical, thermal, magnetic, and spectral studies (IR, UVvisible, ${ }^{1} \mathrm{H}$ NMR, ${ }^{13} \mathrm{C}$ NMR, and EPR). The electronic spectra of the complexes and their magnetic moments suggest tetrahedral geometry for the isolated complexes. The complexes are nonelectrolytes and insoluble in water and common organic solvents but soluble in DMSO.
\end{abstract}

\section{Introduction}

Interaction between transition metals and proteins is ubiquitous in biochemistry [1]. The fundamental intrinsic nature of these interactions can be studied in metal complexes with amino acid Schiff bases [2], which has led to the suggestion that Schiff bases act as a tridentate ligand containing an azomethine nitrogen atom and the terminal two oxygen atoms of the carboxylate group as well as the hydroxyl group [3]. The field of Schiff base complexes has been fast developing on account of the wide variety of possible structures for the ligands depending upon the aldehydes and amines considered, and various Schiff bases were reported to possess genotoxicity [4-6], antibacterial [7, 8], and antifungal activities [9]. The increasing interest in transition metal complexes containing a Schiff base ligand is derived from their well-established role in biological systems as well as their catalytic and pharmaceutical applications $[10,11]$.

Although the chemistry and spectroscopy of metal complexes of Schiff bases derived from aldehydes and/or ketones and amino acids have been widely studied, rather less is known about their antibiotic analogues. A literature survey revealed that little work involving metal-based antibiotics has been reported so far. Cefotaxime is a third generation cephalosporin antibiotic; like other $\beta$-lactam antibiotics, it has a broad-spectrum antimicrobial activity [12]. Since the coordination environments of metals in metal-based antibiotics is not well-known and continuing with our studies in order to shed more light on the nature of mono- and polynuclear Schiff base complexes containing antibiotics [1318], we report here the isolation and characterization of metal(II) complexes containing a Schiff base ligand derived from cefotaxime antibiotic and salicylaldehyde.

\section{Experimental}

2.1. Materials and Methods. All necessary precautions were taken to exclude oxygen and moisture during the synthesis and handling of the compounds. Analytical grade chemicals were used as received for all experiments. Fourier transform infrared (FTIR) spectra of the ligand and its metal complexes as $\mathrm{KBr}$ pellets were recorded in the spectral range 4,000$400 \mathrm{~cm}^{-1}$ with a Perkin-Elmer Series 2000 apparatus. Measurements of $\mathrm{d}-\mathrm{d}$ transitions in the visible and near infrared 
region were taken with a Cary Recording Spectrophotometer Model 17D, while a Perkin-Elmer Spectrophotometer was used for recording the visible and u.v. regions. The contents of C, H, N, and S were analysed on a LECO CHNS 932 model microanalytical instrument. The complexes were analyzed for their metal content with a Perkin-Elmer atomic absorption analyzer, after decomposition with a mixture of $\mathrm{HNO}_{3}$ and $\mathrm{HCl}$ followed by $\mathrm{H}_{2} \mathrm{SO}_{4}$. Thermograms were recorded on a simultaneous thermal analyzer, STA-6000 (Perkin-Elmer) instrument in air and a heating rate of $4^{\circ} \mathrm{C} \mathrm{min}^{-1}$ up to $200^{\circ} \mathrm{C}$. Magnetic susceptibilities were measured on a Johnson Matthey Susceptibility Balance at room temperature using $\mathrm{Hg}\left[\mathrm{Co}(\mathrm{NCS})_{4}\right]$ as calibrant. EPR spectra were recorded on a Bruker ECS 106 spectrometer by the X-band. ${ }^{1} \mathrm{H}$ and ${ }^{13} \mathrm{C}$ NMR spectra were measured in deuterated DMSO on a Jeol $400 \mathrm{MHz}$ spectrometer. All NMR studies were performed at room temperature, and the chemical shift values were determined in relation to $\mathrm{SiMe}_{4}$.

2.2. Synthesis of Salicilydene-Cefotaxime Ligand $\left(\mathrm{H}_{2} L\right)$. To $1 \mathrm{mmol}$ of cefotaxime in $250 \mathrm{~mL}$ of hot ethanol was added $1 \mathrm{mmol}$ of salicylaldehyde. The solution was refluxed under nitrogen atmosphere at $50^{\circ} \mathrm{C}$ for 30 min to give a dark yellow precipitate. This material was filtered off and washed with ethanol and ether and dried under reduced pressure. The product was purified by recrystallization from the same solvent (yield 65\%), m.p. $150-152^{\circ}$ C. ${ }^{1} \mathrm{H}$ NMR $\left(\right.$ DMSO- $_{6}, \delta$, ppm): 7.2-7.7 (m, 4H, -phenyl), 10.2 (s, 1H, -OH), 8.7 (s, $1 \mathrm{H}$, $\mathrm{HC}=\mathrm{N}), 11.0$ (s, 1H, -COOH), 7.6 (s, 1H, thiazole), 9.1 (s, 1H, -NH-CO-), 6.1 (d, 1H, J = 7.2, $\beta$-lactam), 6.3 (d, 1H, $J=$ 7.4, $\beta$-lactam), 4.8 (s, $2 \mathrm{H}, \mathrm{CH}_{2} \mathrm{O}$ ), 2.1 (s, $2 \mathrm{H}$, six-membered thiazole ring), $1.9\left(\mathrm{~s}, 6 \mathrm{H}, \mathrm{CH}_{3}\right) ;{ }^{13} \mathrm{C} \mathrm{NMR}$ (DMSO- $\mathrm{d}_{6}, \delta$, ppm): $170.45\left(\mathrm{C}_{15}\right.$, five-membered thiazole ring $), 168.39\left(\mathrm{C}_{12}\right.$, $-\mathrm{C}=\mathrm{N}), 163.62\left(\mathrm{C}_{17},-\mathrm{CH}=\mathrm{N}\right), 163.43\left(\mathrm{C}_{11},-\mathrm{HN}-\mathrm{CO}\right), 163.02$ $\left(\mathrm{C}_{2}, \beta\right.$-lactam $), 161.50\left(\mathrm{C}_{7},-\mathrm{COOH}\right), 157.82\left(\mathrm{C}_{19},-\mathrm{OH}-\mathrm{ph}\right)$, $142.61\left(\mathrm{C}_{5}\right), 132.24,130.46,121.25,118.45,115.82\left(\mathrm{C}_{18}, \mathrm{C}_{20}-\mathrm{C}_{23}\right.$ phenyl), $58.12\left(\mathrm{C}_{3}, \beta\right.$-lactam ring $), 57.33\left(\mathrm{C}_{1}, \beta\right.$-lactam ring), $49.23\left(\mathrm{C}_{8},-\mathrm{CH}_{2}\right)$. Anal. Calcd. for $\left(\mathrm{H}_{2} \mathrm{~L}\right)\left(\mathrm{C}_{23} \mathrm{H}_{21} \mathrm{~N}_{5} \mathrm{O}_{8} \mathrm{~S}_{2}\right)$ (\%): C, 49.4; N, 12.5; H, 3.8; S, 11.4. Found: C, 49.3; N, 12.3; $\mathrm{H}, 3.8 ; \mathrm{S}, 11.2$.

2.3. Synthesis of Mono- $[M(L)](M(I I)=C o, N i$, and $\mathrm{Cu})$ and Tetranuclear Schiff Base Complexes $\left[M_{4}(\mathrm{~L})(\mathrm{OH})_{6}\right](M(I I)=$ $\mathrm{Ni}, \mathrm{Cu}$ ). Cobalt, nickel, and copper complexes were prepared by the same general method. To a hot solution of $1 \mathrm{mmol}$ (or $4 \mathrm{mmol}$ ) of the appropriate $\mathrm{M}(\mathrm{OAc})_{2}$ metal salt in $20 \mathrm{~mL}$ of $\mathrm{MeOH}$ was slowly added with stirring a solution of $1 \mathrm{mmol}$ of $\mathrm{H}_{2} \mathrm{~L}$ in $10 \mathrm{~mL}$ of the same solvent. To this $\mathrm{KOH} 0.1 \%$ of methanol was added to adjust the $\mathrm{pH}$ of the solution at 7-8 and the mixture was refluxed for 2 hours. The metal complexes of $\mathrm{H}_{2} \mathrm{~L}$ were separated from the reaction mixture as amorphous solids and washed several times with $\mathrm{MeOH}$ and ether and dried under reduced pressure at room temperature (yield 35-45\%), m.p. $>250^{\circ} \mathrm{C}$. Anal. Calcd. for $\mathrm{Co}(\mathrm{L}): \mathrm{Co}\left(\mathrm{C}_{23} \mathrm{H}_{19} \mathrm{~N}_{5} \mathrm{O}_{8} \mathrm{~S}_{2}\right)(\%): \mathrm{C}, 44.8 ; \mathrm{N}, 11.4 ; \mathrm{H}, 3.1 ; \mathrm{S}$, 10.4; Co, 9.6. Found: C, 44.5; N, 11.0; H, 3.5; S, 10.1; Co, 9.5. Anal. Calcd. for $\mathrm{NiL}: \mathrm{Ni}\left(\mathrm{C}_{23} \mathrm{H}_{19} \mathrm{~N}_{5} \mathrm{O}_{8} \mathrm{~S}_{2}\right)$ (\%): C, 44.8; $\mathrm{N}$, 9.5; H, 3.1 S, 10.4; Ni, 9.5. Found: C, 44.6; N, 9.8; H, 3.4;
S, 10.6; Ni, 9.2. Anal. Calcd. for $\mathrm{Cu}(\mathrm{L}): \mathrm{Cu}\left(\mathrm{C}_{23} \mathrm{H}_{19} \mathrm{~N}_{5} \mathrm{O}_{8} \mathrm{~S}_{2}\right)$ (\%): C, 44.5; N, 11.3; H, 3.1; S, 10.3; Cu, 10.2. Found: C, 44.1; N, 10.9; H, 2.7; S, 9.8; Cu, 10.1. Anal. Calcd. for $\mathrm{Ni}_{4} \mathrm{~L}(\mathrm{OH})_{6}: \mathrm{Ni}_{4}\left(\mathrm{C}_{23} \mathrm{H}_{25} \mathrm{~N}_{5} \mathrm{O}_{14} \mathrm{~S}_{2}\right)(\%): \mathrm{C}, 30.9 ; \mathrm{N}, 7.8 ; \mathrm{H}, 2.8$ S, 7.2; Ni, 26.3. Found: C, 31.2; N, 8.1; H, 2.9; S, 7.5; Ni, 26.6. Anal. Calcd. for $\mathrm{Cu}_{4}(\mathrm{~L})(\mathrm{OH})_{6}: \mathrm{Cu}_{4}\left(\mathrm{C}_{23} \mathrm{H}_{25} \mathrm{~N}_{5} \mathrm{O}_{14} \mathrm{~S}_{2}\right)(\%)$ : C, 30.2; N, 7.7; H, 2.8; S, 7.0; Cu, 27.8. Found: C, 29.9; N, 7.5; H, 3.1; $\mathrm{S}, 6.8 ; \mathrm{Cu}, 27.9$.

2.4. Synthesis of Dinuclear Schiff Base Complex $\left[\mathrm{Ag}_{2}(\mathrm{~L})(\mathrm{OAc})_{2}\right]$. To a hot solution of $2 \mathrm{mmol}$ of $\mathrm{Ag}$ (OAc) metal salt in $10 \mathrm{~mL}$ of dry $\mathrm{MeOH}$ was slowly added with stirring a solution of $1 \mathrm{mmol}$ of $\mathrm{H}_{2} \mathrm{~L}$ in $10 \mathrm{~mL}$ of the same solvent, under nitrogen atmosphere. The metal(II) complex of $\mathrm{H}_{2} \mathrm{~L}$ was separated from the reaction mixture as amorphous solids and washed several times with $\mathrm{MeOH}$ and ether and dried under reduced pressure at room temperature (yield 50-55\%), m.p. $>250^{\circ} \mathrm{C}$. Anal. Calcd. for $\mathrm{Ag}_{2}(\mathrm{~L})(\mathrm{OAc})_{2}: \mathrm{Ag}_{2}\left(\mathrm{C}_{27} \mathrm{H}_{25} \mathrm{~N}_{5} \mathrm{O}_{12} \mathrm{~S}_{2}\right)(\%): \mathrm{C}, 36.4 ; \mathrm{N}, 7.9 ; \mathrm{H}$, 2.8; S, 7.2; Ag, 24.2. Found: C, 36.5; N, 8.1; H, 3.2; S, 7.1; Ag, 24.1.

\section{Results and Discussion}

Through a condensation reaction an amino group available in the drug substance cefotaxime was allowed to react with salicylaldehyde to form a Schiff base ligand $\mathrm{H}_{2} \mathrm{~L}$ which was, subsequently, reacted with metal ions to form mono- and polynuclear Schiff base metal complexes. The synthetic route of $\mathrm{H}_{2} \mathrm{~L}$ ligand and the [ML] complexes is given in Scheme 1. The ligand and the metal(II) complexes were isolated pure from $\mathrm{MeOH}$ in very good yields and they are of various colors. The ligand is yellow; iron and nickel are green while silver and cobalt are dark red complexes in color. All the complexes did not melt/decompose when heated up to $250^{\circ} \mathrm{C}$. The analytical data of the complexes correspond well with $1: 1$, $2: 1$, or $4: 1$ metal: ligand stoichiometries. Thus, the general formulae $[\mathrm{M}(\mathrm{L})](\mathrm{M}(\mathrm{II})=\mathrm{Co}, \mathrm{Ni}, \mathrm{Cu}),\left[\mathrm{Ag}_{2}(\mathrm{~L})(\mathrm{OAc})_{2}\right]$, and $\left[\mathrm{M}_{4}(\mathrm{~L})(\mathrm{OH})_{6}\right](\mathrm{M}(\mathrm{II})=\mathrm{Ni}, \mathrm{Cu})$ have been assigned to the mono- and polynuclear complexes, respectively, and they are very air stable solids at room temperature without decomposition for a long time. The complexes are insoluble in water and other common organic solvents such as ethanol, chloroform, benzene, acetone, dichloromethane, DMF, acetonitrile, and diethyl ether but soluble in DMSO. Thermograms of the metal complexes indicate that the complexes are stable with no hydration water and solvent molecules. The molar conductance values measured in DMSO at room temperature vary from 7.0 to $16.7 \mathrm{~S} \mathrm{~cm}^{2} \mathrm{~mol}^{-1}$, revealing the nonelectrolytic nature of the complexes [19].

3.1. ${ }^{1} \mathrm{H}$ and ${ }^{13} \mathrm{C}$ NMR Spectra. The NMR spectra of free ligand are reported along with possible assignments in the experimental section. ${ }^{1} \mathrm{H}$ NMR spectrum of the Schiff base ligand was recorded in DMSO- $\mathrm{d}_{6}$. All the protons were found as to be in their expected region [20]. The number of protons and carbons calculated from the integration curves and those obtained from the values of the expected elemental 

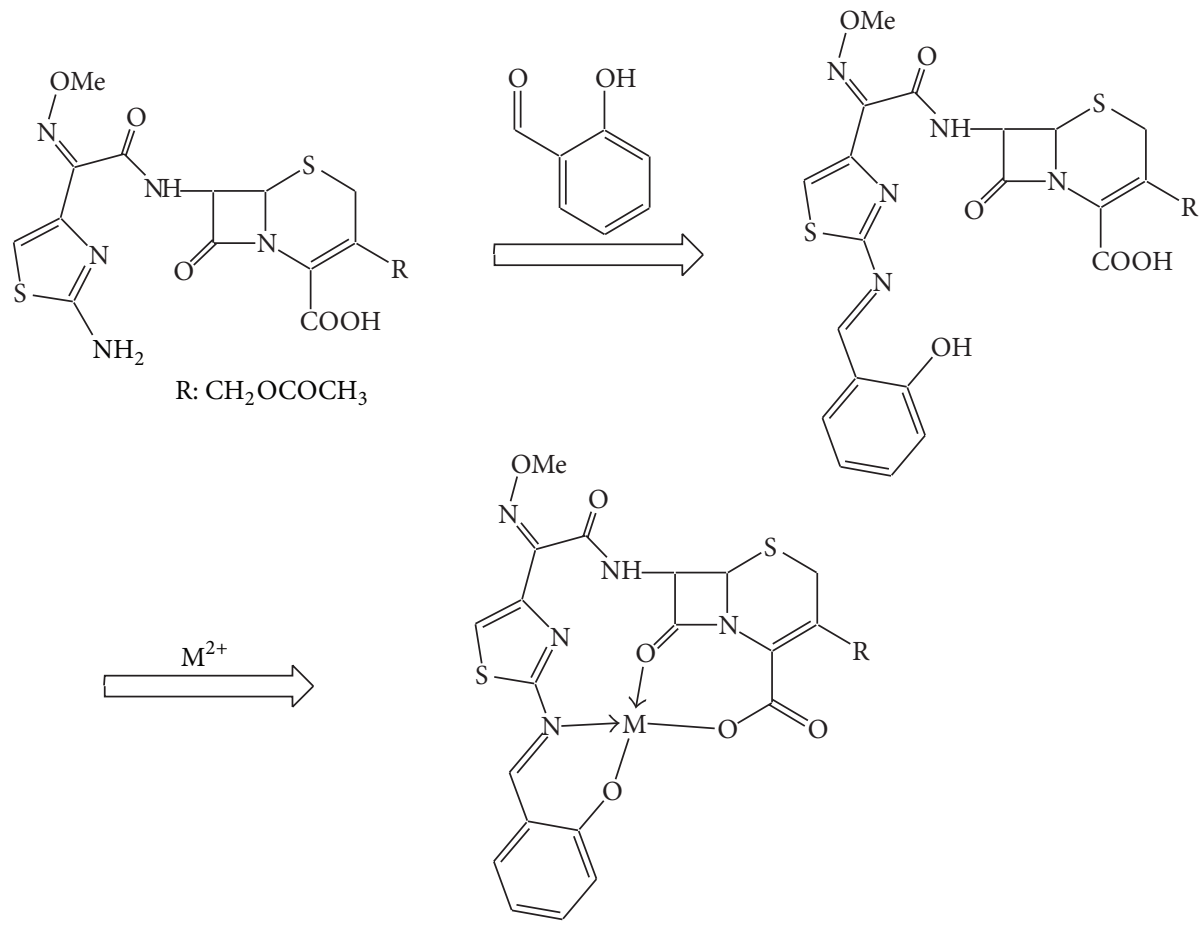

SCHEME 1

TABLE 1: Main IR wavenumbers $\left(\mathrm{cm}^{-1}\right)$.

\begin{tabular}{|c|c|c|c|c|c|}
\hline Compound & $\begin{array}{l}\nu(\mathrm{C}=\mathrm{O}) \\
\text { lactam }\end{array}$ & $\begin{array}{c}\nu(\mathrm{C}=\mathrm{N}) \\
\text { imine }\end{array}$ & $\begin{array}{l}\nu(\mathrm{COO}) \\
\text { asymm. }\end{array}$ & $\begin{array}{c}v(\mathrm{COO}) \\
\text { sym. }\end{array}$ & $\Delta v$ \\
\hline Schiff base & 1740 & 1650 & & & \\
\hline$[\mathrm{Co}(\mathrm{L})]$ & 1730 & 1630 & 1550 & 1340 & 210 \\
\hline$[\mathrm{Ni}(\mathrm{L})]$ & 1730 & 1630 & 1580 & 1360 & 220 \\
\hline$[\mathrm{Cu}(\mathrm{L})]$ & 1730 & 1630 & 1580 & 1360 & 220 \\
\hline$\left[\mathrm{Ag}_{2}(\mathrm{~L})(\mathrm{OAc})_{2}\right]$ & 1750 & 1640 & 1590 & 1380 & 210 \\
\hline$\left[\mathrm{Ni}_{4}(\mathrm{~L})(\mathrm{OH})_{6}\right]$ & 1750 & 1640 & 1580 & 1370 & 210 \\
\hline$\left[\mathrm{Cu}_{4}(\mathrm{~L})(\mathrm{OH})_{6}\right]$ & 1750 & 1640 & 1570 & 1360 & 210 \\
\hline
\end{tabular}

analyses agree well with each other. The paramagnetic nature of the complexes produced precluded detailed studies of the products by NMR spectroscopy. ${ }^{13} \mathrm{C}$ NMR spectrum of salicylidene-cefotaxime ligand was also recorded in DMSO$\mathrm{d}_{6}$. All assignments of the carbon atoms due to heteroatomic and/or aromatic groups were found in their expected region $[20,21]$ and are well supported by their IR and ${ }^{1} \mathrm{H}$ NMR spectra. The results also indicate that the presence of number of carbons agrees well with the expected number of carbons.

3.2. FT-IR Spectra. Infrared spectroscopy provides valuable information as to whether or not condensation to form imine bonds has occurred. The salicylaldehyde produces band close to $1700 \mathrm{~cm}^{-1}$ while the terminal $\mathrm{NH}_{2}$ group of the cefotaxime gives $\mathrm{N}-\mathrm{H}$ stretching vibrations at 3200 and $3300 \mathrm{~cm}^{-1}$. The $\mathrm{C}=\mathrm{N}$ imine band, at $1650 \mathrm{~cm}^{-1}$, does not overlap with the above bands and simple observation of the $1600-1700 \mathrm{~cm}^{-1}$ region indicates the success or failure of a reaction. The spectra of the studied metal(II) complexes show significant bands from 1600 to $1640 \mathrm{~cm}^{-1}$ which may be assigned to $\nu(\mathrm{C}=\mathrm{N})$ stretching modes of the coordinated ligand $\mathrm{H}_{2} \mathrm{~L}$. The shift of this band on complexation towards lower wave numbers indicates coordination of the azomethine nitrogen to the metal center $[22,23]$. The main IR wavenumbers can be seen in Table 1 .

The infrared spectrum of the Schiff base ligand shows a strong absorption band at $1730 \mathrm{~cm}^{-1}$ which can be assigned to lactam $v(\mathrm{C}=\mathrm{O})$ vibrational mode. This band shifted in the metal complexes. The shifts of this band toward higher wavenumbers for polynuclear complexes rather strange but they have been observed in cephalosporin metal complexes of cefazolin [16], ceftriaxone [17], and cephalosporin Schiff base metal complexes [24]. Probably, the absorption band of the lactam carbonyl moiety of the $\mathrm{Ag}_{2}, \mathrm{Ni}_{4}$, and $\mathrm{Cu}_{4}$ complexes was shifted to higher frequency due to greater rigidity shown by this group when coordinated. 
The amide $(\mathrm{C}=\mathrm{O})$ band is unshifted in the complexes compared to the free ligands. Furthermore, the $\mathrm{C}-\mathrm{N}-\mathrm{C}$ stretching and the $\mathrm{N}-\mathrm{H}$ stretching vibrations of the $\mathrm{CONH}$ residues observed in free Schiff base at 1180 and $3240 \mathrm{~cm}^{-1}$, respectively, either do not shift or show a slight shift in all the metal complexes indicating that these $\mathrm{N}$ atoms were not involved in coordination. Given the significant shifts in the lactam $\mathrm{C}=\mathrm{O}$ band in the complexes, we suggest that coordination of the Schiff base ligand occurs through the oxygen atom from the lactam rather than the amide carbonyl group [22].

The $v(\mathrm{C}-\mathrm{OH})$ phenolic stretching frequency of ligand is seen at $1345 \mathrm{~cm}^{-1}$ which gets shifted to a lower frequency region in the complexes in the range of $1332-1326 \mathrm{~cm}^{-1}$, and this is indicative of bonding through phenolic oxygen [25]. Also, disappearance of the stretching frequency at $1710 \mathrm{~cm}^{-1}$ assigned to $v(\mathrm{C}=\mathrm{O})$ from $\mathrm{COOH}$ moiety in the ligand and appearance in the complexes of new $v_{\mathrm{as}}$ and $v_{\mathrm{s}}$ modes of the $\left(-\mathrm{COO}^{-}\right)$group at $1550-1580$ and $1340-1370 \mathrm{~cm}^{-1}$ ranges, respectively, indicate that the Schiff base has reacted. These and the $\Delta v$ value $\left(\nu_{\text {as }}-v_{s}\right)>200 \mathrm{~cm}^{-1}$ are consistent with carboxylate monodentate coordination with the metal atoms. These overall data suggest that the azomethine- $\mathrm{N}$, phenolic$\mathrm{O}$, carboxylate- $\mathrm{O}$, and lactam $\mathrm{C}=\mathrm{O}$ moieties are involved in coordination with the metal(II) ion in complexes and that the Schiff base behaves as a tetradentate ligand.

Furthermore, the appearance of new bands in the 540$490 \mathrm{~cm}^{-1}$ ranges attributed to $\nu(\mathrm{M}-\mathrm{N})$ stretching vibrations, observed in the spectra of the complexes (absent in the free ligand), provides evidence that the $\mathrm{C}=\mathrm{N}$ moiety could be bonded to the metal ion through the nitrogen atom. The complexes also show bands in the 1430-1460, 1070-1100, and $720-740 \mathrm{~cm}^{-1}$ ranges which can be assigned to phenyl ring vibrations. Medium intensity band appearing in the $2850-$ $2950 \mathrm{~cm}^{-1}$ region corresponds to aliphatic $\nu(\mathrm{C}-\mathrm{H})$, while aromatic $v(\mathrm{C}-\mathrm{H})$ stretches appear in the $3000-3100 \mathrm{~cm}^{-1}$ region. Lastly, the bands in the $460-410 \mathrm{~cm}^{-1}$ region observed in all complexes, and absent in the free ligands, could be tentatively assigned to $\nu(\mathrm{M}-\mathrm{O})$ vibrations. A broad band at $3430 \mathrm{~cm}^{-1}$ observed in the $\left[\mathrm{M}_{4}(\mathrm{~L})(\mathrm{OH})_{6}\right]$ complexes is assigned to $v(\mathrm{OH})$.

3.3. Electronic Spectra. The electronic spectra of the Schiff base ligand as well as the complexes in $10^{-3} \mathrm{M}$ DMSO solutions showed two broad bands in the regions 230$280 \mathrm{~nm}$ and $300-335 \mathrm{~nm}$. The former band is assigned to the absorption of $\left({ }^{1} \mathrm{~L}_{\mathrm{b}} \rightarrow{ }^{1} \mathrm{~A}_{1}\right)$ of the benzene ring, while the second band is assigned to $\pi-\pi^{*}(\mathrm{C}=\mathrm{N}-)$ transition of the azomethine group, which is shifted to lower wavelength on coordination [26].

As is known, the electronic spectra of the complexes show that the absorptions around $400-900 \mathrm{~nm}$ are due to ligand to metal charge-transfer and/or d-d transition bands of the metal in the complexes. The electronic spectra of the complexes exhibit two bands at $c a .570-670 \mathrm{~nm}(\varepsilon=$ $\left.148-180 \mathrm{~L} \mathrm{~mol}^{-1} \mathrm{~cm}^{-1}\right)$ and at $c a .420-440 \mathrm{~nm}(\varepsilon=1.16-3.65$ $\left.\times 10^{3} \mathrm{~L} \mathrm{~mol}^{-1} \mathrm{~cm}^{-1}\right)$. The first band is probably due to the
${ }^{4} \mathrm{~A}_{2} \rightarrow{ }^{4} \mathrm{~T}_{1}(\mathrm{P})$ for $[\mathrm{Co}(\mathrm{L})],{ }^{3} \mathrm{~A}_{2} \rightarrow{ }^{3} \mathrm{~T}_{2}(\mathrm{~F})$ for $[\mathrm{Ni}(\mathrm{L})]$, and ${ }^{2} \mathrm{~T}_{2} \rightarrow{ }^{2} \mathrm{E}_{2}(\mathrm{G})$ for $[\mathrm{Cu}(\mathrm{L})]$ transition, and the second due to the charge transfer transition of tetrahedral geometry [27-32]. The $\left[\mathrm{Ag}_{2}(\mathrm{~L})(\mathrm{OAc})_{2}\right]$ and $\left[\mathrm{M}_{4}(\mathrm{~L})(\mathrm{OH})_{6}\right]$ complexes exhibit a band at $420 \sim 430 \mathrm{~nm}$ which may be attributed to the $\mathrm{d}$ - $\mathrm{d}$ transition of the metal in a tetrahedral environment [33]. In addition, they show a strong absorption in the short wavelength range, $385-395 \mathrm{~nm}$, which may be attributed to the charge-transfer absorption bands, due to the spinexchange interaction between the metal ${ }^{\mathrm{II}}$ ions [33].

3.4. Magnetic Measurements. All the complexes are paramagnetic. From the molar magnetic susceptibility values, corrected magnetic moments were calculated using Pascal's constants. The $[\mathrm{Co}(\mathrm{L})]$ complex has a magnetic moment of 4.50 B.M. typical for high spin $\mathrm{d}^{7}$ systems with three unpaired electrons. The value observed for this complex is higher than the value expected for square-planar geometry (2.1-2.8) and consistent with the value expected for high spin tetrahedral geometry [34]. The $[\mathrm{Ni}(\mathrm{L})]$ complex has a magnetic moment of 3.72 B.M. as predicted for high spin $\mathrm{d}^{8}$ systems with two unpaired electrons and in agreement with the values reported for tetrahedral geometry around the nickel(II) ion [34]. The $[\mathrm{Cu}(\mathrm{L})]$ complex has a magnetic moment of 1.75 B.M. at room temperature, in the range associated with $\mathrm{d}^{9}$ systems with one unpaired electron.

The room temperature EPR spectrum of a powder sample of the $[\mathrm{Cu}(\mathrm{L})]$ complex showed a single signal with poorly resolved hyperfine structure. The EPR spectrum of the $\left[\mathrm{Cu}_{4}(\mathrm{~L})(\mathrm{OH})_{6}\right]$ complex also shows a single broad signal with poor resolution of the hyperfine structure on both sides of the main signal and the $\mathrm{g}$ values, $\mathrm{g}_{\|}=2.17$ and $\mathrm{g}_{\perp}=2.05$, and the calculated axial symmetry parameter, $G=3.4$, supports [35] the suggestion that there is no considerable exchange interaction between the copper centers $(G<4)$. In general, polynuclear $\mathrm{Cu}$ (II) complexes give broad EPR peaks and the broadening is assigned to a dipolar interaction [36]. The greater value of $g_{\|}$compared to $g_{\perp}$ proposes a distorted tetrahedral-square pyramidal structure and rules out the possibility of a trigonal bipyramidal structure which is expected to have $g_{\perp}>g_{\|}$. Also, the observed $g_{\|}$values of less than 2.3 provide evidence for the covalent character of bonding between $\mathrm{Cu}(\mathrm{II})$ ion and the ligand $[37,38]$.

For the complex $\left[\mathrm{Ni}_{4}(\mathrm{~L})(\mathrm{OH})_{6}\right]$ the $\chi_{\mathrm{M}} \mathrm{T}$ product at $300 \mathrm{~K}$ is equal to $4.161 \mathrm{~cm}^{3} \mathrm{~mol}^{-1} \mathrm{~K}$ which corresponds to an effective magnetic moment of 5.8 M.B.; this value is similar to the theoretical value expected for four uncoupled nickel(II) ions. For the complex $\left[\mathrm{Cu}_{4}(\mathrm{~L})(\mathrm{OH})_{6}\right]$ the $\chi_{\mathrm{M}} \mathrm{T}$ product is $1.335 \mathrm{~cm}^{3} \mathrm{~mol}^{-1} \mathrm{~K}$ at room temperature which corresponds to an effective magnetic moment of 3.3 M.B.; this value is very close to the theoretical value expected for four independent copper ${ }^{\mathrm{II}}$ ions. Thus, these complexes with noninteracting metal centres have magnetic properties that are the same as seen in the mononuclear complex of the same metal.

Notwithstanding that the synthesis of silver complex was carried out under nitrogen atmosphere, presumably air oxidation occurs and the Schiff base ligand having delocalized $\pi$-orbital system is able to coordinate to the central silver 

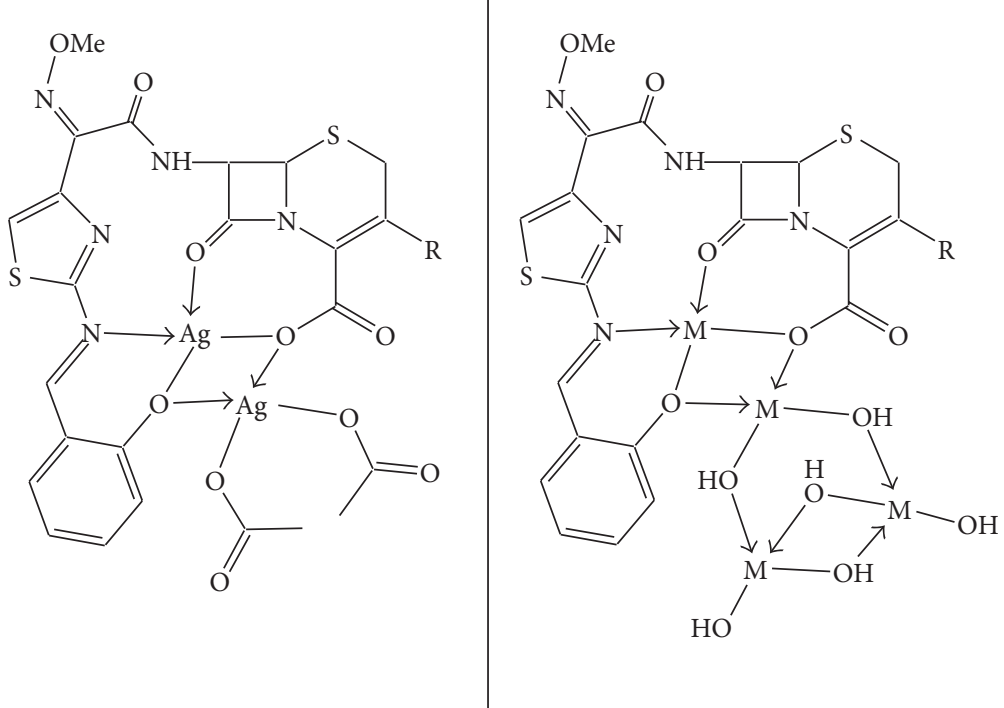

Figure 1: Suggested structures for $\left[\mathrm{Ag}_{2}(\mathrm{~L})(\mathrm{OAc})_{2}\right]$ and $\left[\mathrm{M}_{4}(\mathrm{~L})(\mathrm{OH})_{6}\right]$ complexes.

ion under the form of semiquinone allowing to obtain a paramagnetic complex compound. During the course of our research we observed that addition of silver acetate to an aqueous suspension of a $50 \% \mathrm{MeOH}$ solution of $\mathrm{H}_{2} \mathrm{~L}$ resulted in the disproportionation of silver ${ }^{\mathrm{I}}$ to the free metal and the silver complex at an observable and rather rapid rate, depending on conditions of concentration and temperature. The silver complex, isolated as $\left[\mathrm{Ag}_{2}(\mathrm{~L})(\mathrm{OAc})_{2}\right]$, is a dark red solid which can be conveniently recrystallized from water/dimethylsulphoxide.

The X-band EPR spectrum of a powdered sample of the $\left[\mathrm{Ag}_{2}(\mathrm{~L})(\mathrm{OAc})_{2}\right]$ complex at room temperature revealed the existence of two paramagnetic centres. The first is a semiquinone radical which exhibits a sharp but not so intense one line EPR spectrum centered at $3330 \mathrm{G}, \mathrm{g}=1.99$, and a line width of $70 \mathrm{G}$. This calculated electronic $\mathrm{g}$ factor, which is close to that of the free electron value (2.0023), as well as the relatively small width of the line as compared with the spectra of other complexes, suggests a more pronounced electron density delocalization on the Schiff base ligand, through the silver ion which is large in size and hence more polarizable.

The second paramagnetic centre shows the features of an intense signal centered at $3200 \mathrm{G}$ and total width of $960 \mathrm{G}$, for an $S=1$, dinuclear silver product, with a $g$ value of 2.08 which coincides with those reported earlier [39, 40]. The spectrum exhibits a dissymmetric broad band which indicates a magnetic spin-exchange interaction between the two spins, $S_{\mathrm{Ag}(\mathrm{II})}=1 / 2$ [41]. Thus, the appearance of this EPR signal shows that the silver complex has unpaired electrons with a high density on the silver nuclei, that is, must contains Ag(II).

The hyperfine doublet structure characteristic of the nuclear spins of ${ }^{107} \mathrm{Ag}\left(\mathrm{I}=1 / 2,51.82 \%\right.$, and ${ }^{109} \mathrm{Ag}(\mathrm{I}=$ $1 / 2,48.18 \%$ ) could not be resolved due to the fact that the centres are not diluted and the magnetic moments of each isotope differ by less than $20 \%$. Also, the superhyperfine coupling due to ${ }^{14} \mathrm{~N}$ nucleus was not observed. The obtained signals are a proof of the Schiff base radical character and are in agreement with ascribing the complex structure of a free radical stabilized through the cation. The formation of this novel complex illustrates further the effect of the exceptionally strong ligand field exerted by the salicylidenecefotaxime ligand. This serves to raise antibonding levels ( $\mathrm{d}$ orbitals) in the species of lower oxidation state to such a high energy that electrons are easily removed.

For the complex $\left[\mathrm{Ag}_{2}(\mathrm{~L})(\mathrm{OAc})_{2}\right]$ the $\chi_{\mathrm{M}} \mathrm{T}$ product at $300 \mathrm{~K}$ is equal to $2.880 \mathrm{~cm}^{3} \mathrm{~mol}^{-1} \mathrm{~K}$ which corresponds to an effective magnetic moment of $4.8 \mathrm{M}$.B.; this value is higher than the theoretical value expected for two uncoupled silver(II) ions. The electron spins on two metal centres in an oxocarboxylate complex can have two interactions-a ferromagnetic interaction where both the spins are parallel or an antiferromagnetic interaction where the electron spins are opposite to each other. The different interactions between the spins can be determined by the bond angle between the two metal centres and the bridging oxygen. Studies of hydroxide bridged copper dimers [42] have shown that when the metal centres are close together, the spins will have a ferromagnetic interaction and this would be the case of the Schiff base silver complex.

We have attempted to grow single crystals of the metal chelates but in no case have we had any success, due to their insolubility in common organic solvents. These studies represent a contribution to future crystallographic analyses, which are complicated by the difficulties in obtaining X-ray quality crystals of cephalosporins complexes. Based on the composition of these complexes, their IR, EPR, electronic spectra, conductivity measurements, and magnetic characterization, we propose that polynuclear complexes would have the coordination environment as shown in Figure 1. Similarly, the isolation and characterization of metal(II) complexes containing a Schiff base ligand derived from 
cefixime antibiotic and salicylaldehyde were carried out [24]. Analytical data indicated the formation of $\mathrm{M}$ : Schiff base $(1: 2)$ complexes, in which ligand is bidentate via azomethine$\mathrm{N}$ and deprotonated salicyl-O moiety.

\section{Acknowledgment}

The authors express their sincere thanks to Comision de Investigación from the Universidad de Oriente for financial support.

\section{References}

[1] M. Buhl, "Molecular dynamics of a vanadate-dipeptide complex in aqueous solution," Inorganic Chemistry, vol. 44, no. 18, pp. 6277-6283, 2005.

[2] H. M. Parekh, P. K. Panchal, and M. N. Patel, "Synthesis and antifungal activity of oxovanadium(IV) complexes with Schiff bases," Pharmaceutical Chemistry Journal, vol. 40, no. 9, pp. 494-497, 2006.

[3] P. K. Panchal, P. B. Pansuriya, and M. N. Patel, "Study on increase in toxicity of Schiff bases on microorganism on chelation with metal," Toxicological and Environmental Chemistry, vol. 88, no. 1, pp. 57-64, 2006.

[4] E. I. Solomon and M. D. Lowery, "Electronic structure contributions to function in bioinorganic chemistry," Science, vol. 259, no. 5101, pp. 1575-1581, 1993.

[5] M. Tümer, E. Akgün, S. Toroglu, A. Kayraldız, and L. Dönbak, "Synthesis and characterization of Schiff base metal complexes: their antimicrobial, genotoxicity and electrochemical properties," Journal of Coordination Chemistry, vol. 61, no. 18, pp. 29352949, 2008.

[6] A. Gölcü, M. Tümer, H. Demirelli, and R. A. Wheatley, " $\mathrm{Cd}(\mathrm{II})$ and $\mathrm{Cu}(\mathrm{II})$ complexes of polydentate Schiff base ligands: synthesis, characterization, properties and biological activity," Inorganica Chimica Acta, vol. 358, no. 6, pp. 1785-1797, 2005.

[7] C. Gerdemann, C. Eicken, and B. Krebs, “The crystal structure of catechol oxidase: new insight into the function of type-3 copper proteins," Accounts of Chemical Research, vol. 35, no. 3, pp. 183-191, 2002.

[8] M. Tümer, N. Deligonul, A. Gölcü et al., "Mixed-ligand copper(II) complexes: investigation of their spectroscopic, catalysis, antimicrobial and potentiometric properties," Transition Metal Chemistry, vol. 31, no. 1, pp. 1-12, 2006.

[9] M. Tümer, H. Köksal, S. Serin et al., "Antimicrobial activity studies of mononuclear and binuclear mixed-ligand copper(II) complexes derived from Schiff base ligands and 1,10phenanthroline," Transition Metal Chemistry, vol. 24, no. 1, pp. 13-17, 1999.

[10] D. Rehder, G. Santoni, G. M. Licini, C. Schulzke, and B. Meier, "The medicinal and catalytic potential of model complexes of vanadate-dependent haloperoxidases," Coordination Chemistry Reviews, vol. 237, no. 1-2, pp. 53-63, 2003.

[11] D. Rehder, "Biological and medicinal aspects of vanadium," Inorganic Chemistry Communications, vol. 6, no. 5, pp. 604-617, 2003.

[12] G. R. Donowitz, “Third generation cephalosporins," Infectious Disease Clinics of North America, vol. 3, no. 3, pp. 595-612, 1989.

[13] J. R. Anacona and L. Brito, "In vitro cytotoxicity and antibacterial activities of cephalosporin Tin(II) complexes," Latin American Journal of Pharmacy, vol. 30, no. 1, p. 172, 2011.
[14] J. R. Anacona, L. Brito, and W. Peña, "Cephalosporin Tin(II) complexes: synthesis, characterization, and antibacterial activity," Synthesis and Reactivity in Inorganic, Metal-Organic, and Nano-Metal Chemistry, vol. 42, no. 9, pp. 1278-1284, 2012.

[15] J. R. Anacona and M. Lopez, "Mixed-ligand nickel(II) complexes containing sulfathiazole and cephalosporin antibiotics: synthesis, characterization, and antibacterial activity," International Journal of Inorganic Chemistry, vol. 2012, Article ID 106187, 8 pages, 2012.

[16] J. R. Anacona and P. Alvarez, "Synthesis and antibacterial activity of metal complexes of cefazolin," Transition Metal Chemistry, vol. 27, no. 8, pp. 856-860, 2002.

[17] J. R. Anacona and A. Rodriguez, "Synthesis and antibacterial activity of ceftriaxone metal complexes," Transition Metal Chemistry, vol. 30, no. 7, pp. 897-901, 2005.

[18] J. R. Anacona and J. J. Santaella, "In vitro antibacterial activity of metal complexes containing a cephaclor derivative ligand," Latin American Journal of Pharmacy, vol. 32, no. 1, pp. 101-106, 2013.

[19] W. Geary, "The use of conductivity measurements in organic solvents for the characterisation of coordination compounds," Coordination Chemistry Reviews, vol. 7, no. 1, pp. 81-122, 1971.

[20] W. W. Simmons, The Sadtler Handbook of Proton NMR SpectraInc, Sadtler Research Laboratories, 1978.

[21] Z. H. Chohan and C. T. Supuran, "Structure and biological properties of first row d-transition metal complexes with $\mathrm{N}$ substituted sulfonamides," Journal of Enzyme Inhibition and Medicinal Chemistry, vol. 23, no. 2, pp. 240-251, 2008.

[22] G. Socrates, Infrared Characteristic Group Frequencies, John Wiley \& Sons, Great Britain, UK, 1980.

[23] K. Nakamoto, Infrared and Raman Spectra of Inorganic and Coordination Compounds, John Wiley \& Sons, New York, NY, USA, 4th edition, 1986.

[24] M. Arif, M. M. R. Qurashi, and M. A. Shad, "Metal-based antibacterial agents: synthesis, characterization, and in vitro biological evaluation of cefixime-derived Schiff bases and their complexes with $\mathrm{Zn}(\mathrm{II}), \mathrm{Cu}(\mathrm{II}), \mathrm{Ni}(\mathrm{II})$, and $\mathrm{Co}(\mathrm{II})$," Journal of Coordination Chemistry, vol. 64, no. 11, pp. 1914-1930, 2011.

[25] M. Sonmez, A. Levent, and M. Sekerci, "Synthesis, characterization, and thermal investigation of some metal complexes containing polydentate ONO-donor heterocyclic Schiff base ligand," Russian Journal of Coordination Chemistry, vol. 30, no. 9, pp. 655-660, 2004.

[26] S. M. E. Khalil, H. S. Seleem, B. A. El-Shetary, and M. Shebl, "Mono- and Bi-nuclear metal complexes of Schiff-base hydrazone $(\mathrm{ONN})$ derived from $o$-hydroxyacetophenone and 2-amino-4-hydrazino-6-methyl pyrimidine," Journal of Coordination Chemistry, vol. 55, no. 8, pp. 883-899, 2002.

[27] F. A. Cotton and G. Wilkinson, Advanced Inorganic Chemistry, Wiley-Interscience, 5th edition, 1988.

[28] M. M. Aboaly and M. M. H. Khalil, "Synthesis and spectroscopic study of $\mathrm{Cu}(\mathrm{II}), \mathrm{Ni}(\mathrm{II})$, and $\mathrm{Co}(\mathrm{II})$ complexes of the ligand salicylidene-2-amino thiophenol," Spectroscopy Letters, vol. 34, no. 4, pp. 498-504, 2001.

[29] I. Sakiyan and H. Yilmaz, "Manganese(III) complexes of some amino acid (L-Serine, L-Methionine, L-Cystein) Schiff bases derived from 2-hydroxy-1-naphthaldehyde," Synthesis and Reactivity in Inorganic, Metal-Organic, and Nano-Metal Chemistry, vol. 33, no. 6, pp. 971-983, 2003.

[30] I. Sakiyan, N. Gunduz, and T. Gunduz, "Synthesis and characterization of manganese(III) complexes of Schiff bases derived 
from amino acids and 2-hydroxy-1-naphthaldehyde," Synthesis and Reactivity in Inorganic and Metal-Organic Chemistry, vol. 31, no. 7, pp. 1175-1187, 2001.

[31] M. Castillo, J. J. Criado, B. Macias, and M. V. Vaquero, "Chemistry of dithiocarbamate derivatives of amino acids. I. Study of some dithiocarbamate derivatives of linear $\alpha$-amino acids and their nickel(II) complexes," Inorganica Chimica Acta, vol. 124, no. 3, pp. 127-132, 1986.

[32] D. X. West, A. K. El-Sawaf, and G. A. Bain, "Metal complexes of N(4)-substituted analogues of the antiviral drug methisazone 1-methylisatin thiosemicarbazone," Transition Metal Chemistry, vol. 23, no. 1, pp. 1-6, 1998.

[33] Y. T. Li, C. W. Yan, and X. C. Zeng, "Heterobinuclear copper(II)-lanthanoid(III) complexes bridged by $\mathrm{N}, \mathrm{N}^{\prime}$-oxamidobis(benzoato)cuprate(II)," Transition Metal Chemistry, vol. 26, no. 1-2, pp. 110-115, 2001.

[34] K. A. R. Salib, A. A. Saleh, S. Abu El-Wafa, and H. F. O. El-Shafiy, "Preparation and characterization of novel asymmetrical Schiff-base ligands derived from 2-methyl-7-formyl8-hydroxyquinoline and their metal complexes," Journal of Coordination Chemistry, vol. 56, no. 4, pp. 283-298, 2003.

[35] M. Shakir, S. P. Varkey, and P. S. Hameed, "Synthesis and spectral studies of binuclear transition metal complexes of diamidediimine hexaazamacrocycles," Polyhedron, vol. 13, no. 9, pp. 1355-1361, 1994.

[36] M. C. Jain, A. K. Shrivastava, and P. C. Jain, "Some tetragonally distorted copper(II) complexes of 4-benzylamidothiosemicarbazide and its thiosemicarbazone," Inorganica Chimica Acta, vol. 23, pp. 199-203, 1977.

[37] S. I. Al-Resayes, M. Shakir, A. Abbasi, M. Y. Amin, and A. Lateef, "Synthesis, spectroscopic characterization and biological activities of $\mathrm{N}_{4} \mathrm{O}_{2}$ Schiff base ligand and its metal complexes of $\mathrm{Co}(\mathrm{II}), \mathrm{Ni}(\mathrm{II}), \mathrm{Cu}(\mathrm{II})$ and $\mathrm{Zn}(\mathrm{II})$, " Spectrochimica Acta A, vol. 93, pp. 86-94, 2012.

[38] E. Akila, M. Usharani, and R. Rajavel, "Design, synthesis and interpretation of binuclear Schiff base metal complexes and their application; antibacterial activity," International Journal of Inorganic and Bioinorganic Chemistry, vol. 2, no. 2, pp. 15-19, 2011.

[39] F. K. Kneubuhl, W. S. Koski, and W. S. Caughey, "An electron spin resonance study of silver porphyrin," Journal of the American Chemical Society, vol. 83, no. 7, pp. 1607-1609, 1961.

[40] M. Ghazzali, A. M. Morsy, A. Youssef et al., "Synthesis, EPR and DFT calculations of rare $\mathrm{Ag}(\mathrm{II})$ porphyrins and the crystal structure of [Zn(II)tetrakis(4-bromo-2-thiophene)porphyrin]," Inorganic Chemistry Communications, vol. 11, no. 9, pp. 10191022, 2008.

[41] A. Bencini, C. Benelli, A. Caneschi, R. L. Carlin, A. Dei, and D. Gatteschi, "Crystal and molecular structure of and magnetic coupling in two complexes containing gadolinium(III) and copper(II) ions," Journal of the American Chemical Society, vol. 107, no. 26, pp. 8128-8136, 1985.

[42] V. H. Crawford, H. W. Richardson, J. R. Wasson, D. J. Hodgson, and W. E. Hatfield, "Relationship between the singlet-triplet splitting and the $\mathrm{Cu}-\mathrm{O}-\mathrm{Cu}$ bridge angle in hydroxo-bridged copper dimers," Inorganic Chemistry, vol. 15, no. 9, pp. 21072110, 1976. 

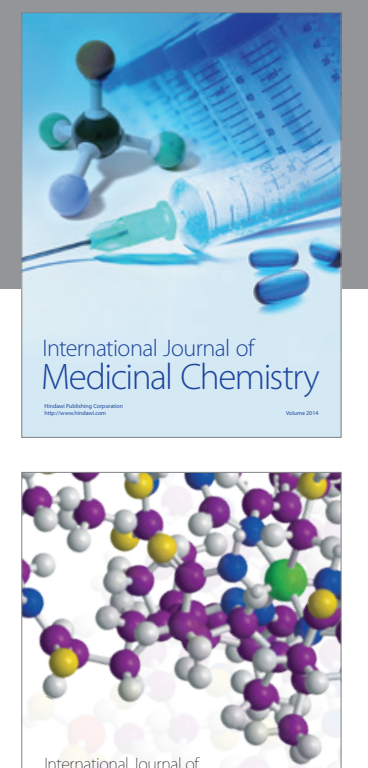

\section{Carbohydrate} Chemistry

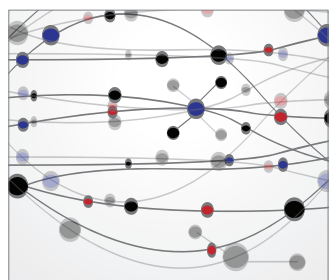

The Scientific World Journal
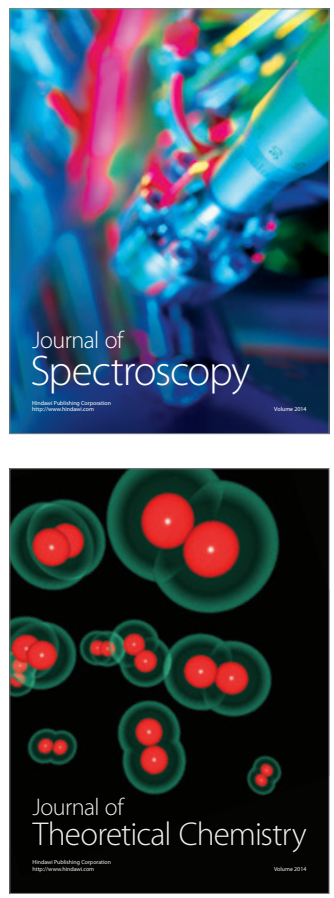
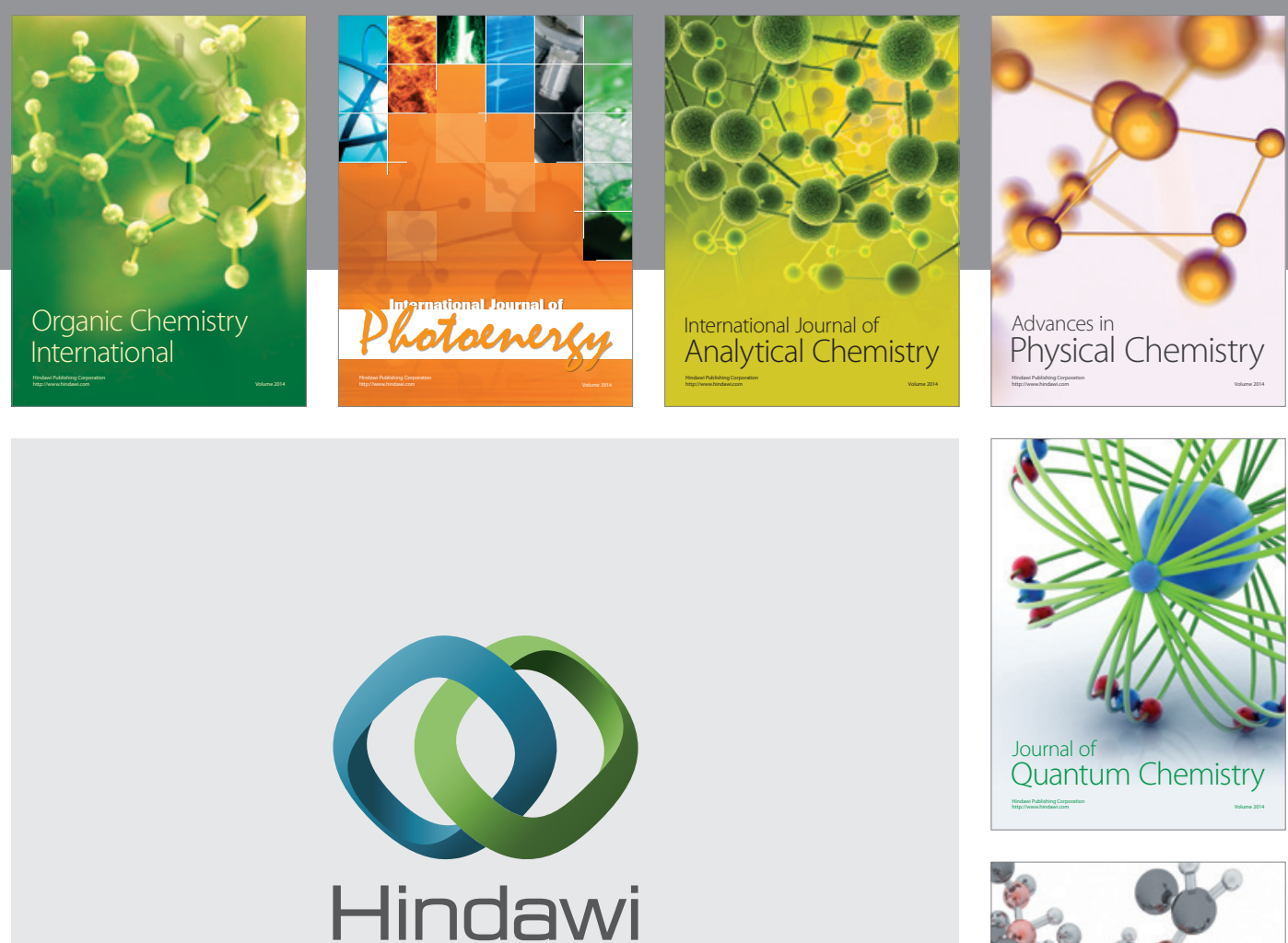

Submit your manuscripts at

http://www.hindawi.com

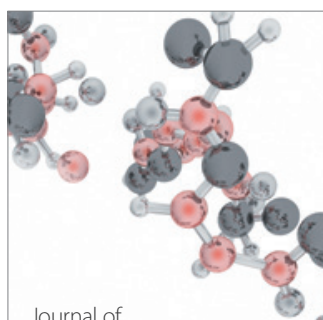

Analytical Methods

in Chemistry

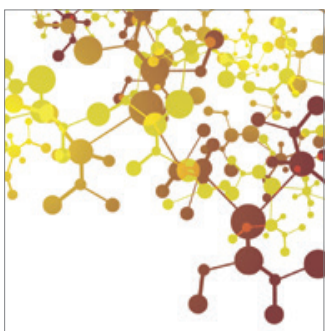

Journal of

Applied Chemistry

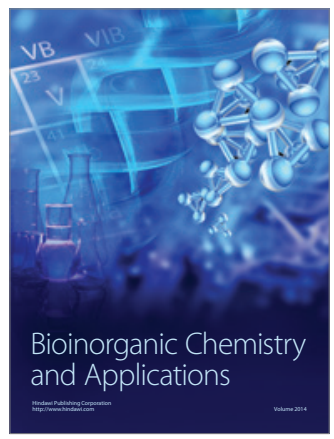

Inorganic Chemistry
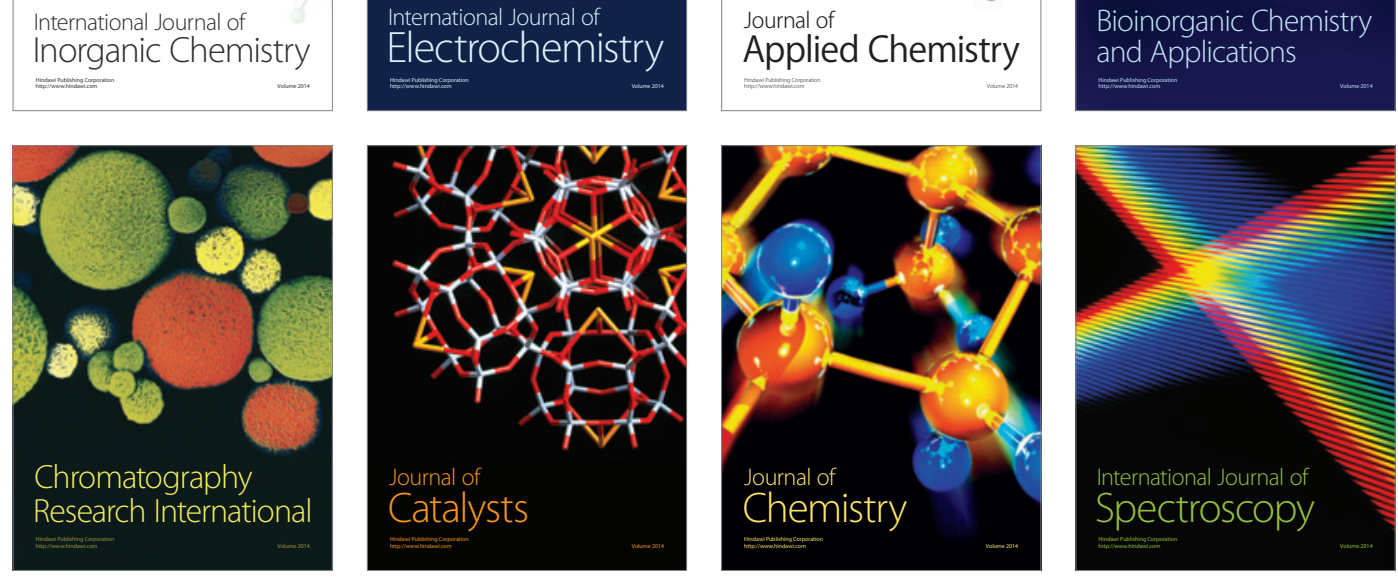